\title{
Parathyroid Gland
}

National Cancer Institute

\section{Source}

National Cancer Institute. Parathyroid Gland. NCI Thesaurus. Code C12765.

One of two small paired endocrine glands, superior and inferior, usually found embedded in the connective tissue capsule on the posterior surface of the thyroid gland; these glands secrete parathyroid hormone that regulates the metabolism of calcium and phosphorus. The parenchyma is composed of chief and oxyphilic cells arranged in anastomosing cords. 